Published in final edited form as:

Oral Surg Oral Med Oral Pathol Oral Radiol Endod. 2010 May ; 109(5): e75-e81. doi:10.1016/j.tripleo. 2009.12.034.

\title{
Innovative endodontic therapy for anti-inflammatory direct pulp capping of permanent teeth with a mature apex
}

Takashi Komabayashi, DDS, M.Dent.Sc., PhD [Assistant Professor] ${ }^{*}$ and Qiang Zhu, DDS, PhD [Associate Professor]

"Department of Endodontics, Texas A\&M Health Science Center Baylor College of Dentistry

${ }^{*}$ Division of Endodontology, Department of Oral Health and Diagnostic Sciences, School of Dental Medicine, University of Connecticut

\section{Abstract}

Direct pulp capping is a treatment of an exposed vital pulp with a dental material to facilitate the formation of reparative dentin and maintenance of vital pulp. It has been studied as an alternate way to avoid vital pulp extirpation. However, the success rate of pulp capping is much lower than that of vital pulp extirpation. Therefore, direct pulp capping is currently considered controversial by many clinicians. To increase success rate, a critical need exists to develop new biologically-based therapeutics that reduce pulp inflammation, promote the continued formation of new dentin-pulp complex, and restore vitality by stimulating the regrowth of pulpal tissue. Bioengineered antiinflammatory direct pulp capping materials, together with adhesive materials for leakage prevention, have great potential to improve the condition of the existing pulp from an inflamed to a non-inflamed status and lead to a high rate of long-term success.

\section{Keywords}

Direct pulp capping; Vital pulp therapy; Pulp tissue regeneration; Pulp Inflammation;

Bioengineering; Dental pulp tissue engineering; Pulp capping material; Endodontic treatment; Pulp extirpation; Outcome; Caries-exposed

\section{Introduction}

The conventional technique of direct pulp capping of permanent teeth with a mature apex is currently considered controversial by many clinicians. Since much of the available information on direct pulp capping is more than a quarter-century old, this review aims to discuss this treatment modality in light of more recent findings.

An understanding of the components of pulp anatomy and biology is necessary to any discussion of endodontic treatment. The pulp, consisting of loose connective tissue, is enclosed by the dentin, which develops from the pulp and is closely connected to the pulp tissue through the odontoblast cells that form portions of both the dental pulp and the dentin body. The dentin

\footnotetext{
Takashi Komabayashi DDS, M.Dent.Sc., PhD, Assistant Professor, Department of Endodontics, Texas A\&M Health Science Center Baylor College of Dentistry, 3302 Gaston Avenue, Dallas, TX 75246 USA, Tel: 214-828-8365 Fax: 214-874-4507,

tkomabayashi@bcd.tamhsc.edu, ICD38719@nifty.com.

Publisher's Disclaimer: This is a PDF file of an unedited manuscript that has been accepted for publication. As a service to our customers we are providing this early version of the manuscript. The manuscript will undergo copyediting, typesetting, and review of the resulting proof before it is published in its final citable form. Please note that during the production process errors may be discovered which could affect the content, and all legal disclaimers that apply to the journal pertain.
} 
is a composite of apatite crystal filler particles in a collagen matrix and is penetrated by the extensions of the odontoblast cells. The mineralized matrix is formed developmentally by the odontoblasts, which begin secreting collagen at the dentinoenamel junction (DEJ) and then grow centripetally, while trailing the odontoblast processes. The odontoblastic processes encased in the dentin tubules make the primary and secondary dentin tubular ${ }^{1-2}$. Since the circumference of the most peripheral part of the crown or root of the tooth is much larger than the circumference of the final pulp chamber or root canal space, the odontoblasts are forced closer together as they continue to lay down dentin, eventually forming a columnar layer in parts of the coronal pulp, especially over the pulp horns ${ }^{3}$. The convergence of the dentinal tubules toward the pulp gives the dentin a unique structural organization, which has profound functional consequences ${ }^{2}$. The odontoblasts also secrete tertiary dentin (reparative dentin) either when irritated by the chemicals diffusing through the dentin, which insults the odontoblasts, or when toxic bacterial metabolites diffuse down the dentinal tubules during a carious attack.

Endodontic diseases are caused by micro-organisms. In 1965, Kakehashi et al. used the pulp of germ-free rats to demonstrate that pulp exposure to the oral cavity did not result in progressive pulp necrosis and periradicular disease. On the contrary, progressive pulp necrosis and the development of periradicular disease always occurred in the presence of microorganisms ${ }^{4}$, a discovery that was later confirmed in humans ${ }^{5}$. Complex endodontic treatment, also known as root canal treatment, is necessary when the dental pulp becomes inflamed and/ or infected. Although the exact numbers are unknown, it has been estimated that more than 22 million root canal treatments are rendered each year in the United States ${ }^{6}$. Of these, several million cases fail, identified by the reoccurrence of symptoms in the patient or through the detection of periradicular disease ${ }^{7}$. Failure to control infections is always the cause for these treatment failures, but technical complications such as root perforations, failure to identify all pulp ramifications, and substandard hydraulic quality of the root canal filling are contributing factors ${ }^{8}$. The very complicated anatomy of the pulp complex makes thorough disinfection difficult.

Pulp extirpation, which is the standard procedure when treating inflamed vital pulps, is technically very challenging. The complete removal of the dental pulp is accomplished using a cleaning and shaping technique inside the root canal, after which a root filling is placed to protect the apically located connective tissue wound. This procedure may require several treatment visits, often costing a few thousand U.S. dollars.

Pulp capping is often practiced as an alternative to pulp extirpation. The American Association of Endodontists (AAE) glossary defines "pulp cap" as "treatment of an exposed vital pulp by sealing the pulpal wound with a dental material such as calcium hydroxide or mineral trioxide aggregate to facilitate the formation of reparative dentin and maintenance of vital pulp." Considering the morphology of the dental pulp space, pulp capping is a seemingly preferable therapy compared to pulp extirpation. From a biological standpoint, the most desirable treatment outcome for any endodontic treatment is to preserve the vital pulp, thus promoting a normally functioning dentin/pulp complex. The dental pulp is one of the most innervated tissues in the body, and it is still not entirely clear what its purpose may be. It has been speculated that some of these nerves may have proprioceptor functions protecting the tooth from overload. A Swedish research team studied this situation by loading vital or non-vital teeth with cantilever weight ${ }^{9}$. Much more weight could be placed on a root-filled tooth before pain was experienced. These findings suggest that the removal of the dental pulp may result in a loss of a protective function.

From a clinical/technical standpoint, pulp capping is technically easier to perform than pulp extirpation. Pulp capping also allows direct inspection of the wound area. Direct capping is a 
proposed therapeutic treatment modality for exposed vital dental pulps. The pulp exposure may be the result of advanced caries or a traumatic exposure. Direct pulp capping was developed as a way of simplifying the treatment and preserving most of the dental pulp. After removal of any caries, direct pulp capping requires the surgical removal of some of the inflamed/infected coronal pulp. Depending on the severity of the pulp disease, this process may entail surgical excision, ranging from minimal to complete removal of the coronal pulp. This treatment is relatively simple to perform and may be done at a fraction of the cost of a pulp extirpation followed by a root canal filling. However, the success rate for a direct pulp capping treatment has, until now, been considered inferior to vital pulp extirpation.

From a public health point of view, however, it is time to reconsider whether, given the recent advances in tissue management and wound healing, all diseased vital pulps require pulp extirpation for optimal healing and success. Stanley ${ }^{10}$ and Bender ${ }^{11}$ have pointed out that a number of pulps are extirpated that could have been saved through the conservative approach of direct pulp capping. Many teeth are diagnosed with reversible pulpitis, which by definition does not require complete removal of the pulp; nevertheless, many such pulps are extirpated as though they had irreversible pulpitis. Direct pulp capping of mature teeth is considered controversial by endodontists who prefer the removal of the entire pulp ${ }^{12}$.

A comparison of the additional costs involved in direct pulp capping versus the conventional removal of all the pulp in root canal treatment indicates that direct pulp capping is less expensive and requires less treatment time. Since this treatment is more likely to be accepted by the patient, unnecessary tooth extraction due to the patient's refusal and fear of conventional root canal treatment can be minimized. Because endodontic failure affects workplace productivity due to unavoidable sick days, a successful outcome of patient treatment using the new direct pulp capping material and technique goes beyond the patient and benefits the family, employer, and community. The cost containment of new direct pulp capping materials and technique will be achieved by decreasing the direct and indirect expenses and increasing the success rate.

\section{Direct pulp capping: Uncertain clinical outcome of caries-exposed vital pulp}

Method of preserving vital pulp are classified according to two types of pulp exposure: mechanical and carious. According to the recent AAE glossary definition, mechanical pulp exposure refers to an "accidental exposure of the pulp by hand- or engine-driven dental instruments in the absence of dental caries." Also, traumatic injuries, such as the fracture of a tooth with vital pulp, mimic mechanical pulp exposure. If aseptic conditions are maintained, the underlying pulp usually does not become inflamed or infected. In contrast, carious pulp exposure refers to that which "results from the progressive destruction of the tooth's structure by acids and proteolytic enzymes that have been synthesized through microbial activity." According to Langeland et al. ${ }^{13}$ and Lin and Langeland ${ }^{14}$, the underlying pulp becomes inflamed to a varying and unknown degree, depending on the extent of the dental caries. As yet, there are no reliable means available to guide clinicians in determining how advanced the inflammation is in caries-exposed vital pulp. The report by Lin and Langeland describes a current clinical modality for complete pulp removal of caries-exposed vital pulp. Further, in the treatment of deep caries, clinicians run the risk of infected dentin chips entering the pulp tissue proper. Thus, in vital pulp, the coronal pulp is usually infected by dental caries, while the apical pulp remains vital with a varying degree of inflammation; nevertheless, complete removal of all pulp is currently exercised.

About 80 years ago, it was discovered that wound treatment with calcium hydroxide in a water vehicle was effective at repairing the exposure site ${ }^{15-19}$. Vital pulp capping was frequently studied by European researchers until the Second World War. With the significant contributions of Hermann, calcium hydroxide has been used extensively in endodontic 
therapies for the disinfection of infected root canals ${ }^{20}$ and for vital pulp therapies ${ }^{19}$. Zander 15 introduced German techniques for pulp capping to North America as an immigrant dentist. Although it does not occur consistently ${ }^{16}$, the hard-tissue repair response has been considered a desirable outcome, since wound treatment with calcium hydroxide in a water vehicle indicates pulp healing. Despite the fact that pulpal healing and repair have been reported at a high rate in both experimental and clinical follow-up studies in cases where the tissue was injured either by caries or accidental trauma ${ }^{21-24}$, capping of the exposed pulp has remained controversial for adult dentition $10,25-27$.

Unfortunately, the clinical outcome of conventional pulp capping is very uncertain as to the survival of the vital pulp ${ }^{28}$. Tronstad and Mjör ${ }^{29}$ reported that the outcome of caries-exposure pulp capping had less than a $50 \%$ chance of success. Al-Hiyasat et al. ${ }^{30}$ examined the treatment outcome of pulp capping for both mechanical and caries exposure. Three years after the procedure, patients were recalled, and their teeth were evaluated using radiography only. The success rate was markedly different for the two types of exposure, with the repair of mechanical exposure producing a $92 \%$ success rate, compared to a mere $33 \%$ for the caries-exposure cases. Likewise, Barthel et al. ${ }^{31}$ examined the treatment outcome of pulp capping using $\mathrm{Ca}(\mathrm{OH})_{2}$ for caries exposure after an elapsed time of 5 and 10 years. The patients were recalled, and their teeth were evaluated using both radiography and pulp vitality testing. The success rates for 5 and 10 years were $37 \%$ and $13 \%$, respectively. Most of the failures in these reports were asymptomatic; the pulp tended to become necrotic slowly. Thus, most clinicians hesitate to do a direct pulp capping treatment, believing this option should be reserved only for teeth displaying minimal signs of pulpitis. Such a clinical strategy is currently still advocated 27 , 32-33.

\section{Ideal pulp wound healing and feasibility of capping}

The ideal healing of a pulp wound results in a solid hard tissue deposit on tubular dentin. Such dentin healing stops when the repair is complete. Thus, calcific changes of the pulp tissue (calcific metamorphosis) are abnormal, signaling a biological breakdown in tissue function. According to Stanley ${ }^{10}$, canal obliteration and internal resorption are the two main pulpal concerns about direct pulp capping. Superficial pulp surgery or a pulpotomy is intended to preserve major portions of the pulp as a functional organ. The AAE glossary defines "pulpotomy (pulp amputation)" as "the surgical removal of the coronal portion of a vital pulp as a means of preserving the vitality of the remaining radicular portion."

In 1978, Cvek 22 designed a superficial pulp surgery, which he termed "partial pulpotomy", utilizing a pulp-cutting technique described by Granath and Hagman ${ }^{34}$. The pulp tissue is atraumatically cut with an end-cutting diamond at high speed with copious irrigation. The wound surface is smoothed and completely debrided and cleaned before being capped. This surgical technique for superficial pulp surgery has been well established in papers by Granath and Hagman ${ }^{34}$, Schröder ${ }^{17,} 35$, Schröder and Granath ${ }^{36-37}$, and Cvek and colleagues 22 , 38-40. Cvek investigated whether the wound can be induced at different levels of the coronal pulp. A limited case series of clinical follow-up treatments using such measures showed that the five-year pulpal survival rate in young teeth with penetrating caries might be as high as $90 \%$ 22, 24, 39, 41; however, no such data exist on more mature adult teeth. In the AAE glossary, "Cvek pulpotomy" is also synonymous with "shallow pulpotomy" or "partial pulpotomy" and is defined as "the surgical removal of the coronal portion of a vital pulp as a means of preserving the vitality of the remaining coronal and radicular pulp tissues."

An important issue to consider with this treatment is the feasibility of the capping procedure. In contemporary restorative dentistry, many materials can be retained in a large cavity through various bonding procedures, which eliminates the need for a post and access to the root canal. Thus, superficial pulp surgery or pulpotomy is an option if the technique can be mastered. We 
now have restorative materials producing a bacteria-tight closing that protects the wound area from oral ingress. Direct pulp capping is used for closed-apex permanent teeth to treat exposed vital pulp using dental materials such as calcium hydroxide, bonded composite resins, and mineral trioxide aggregate; the purpose of these materials is to facilitate both the formation of reparative dentin and the maintenance of vital pulp $28,42-43$. Calcium hydroxide-mediated hard tissue repair is thought to provide such protective functions ${ }^{10,17}$. However, Schröder 17 suggests that a necrotic layer of tissue initially forms beneath the $\mathrm{Ca}(\mathrm{OH})_{2}$ after a direct pulp cap. While it is known that calcium hydroxide is a nearly ideal wound dressing, it would be worthwhile to find a better material for wound dressing, possibly one with bioactive functions or growth factors. In 1985, Cox et al. ${ }^{44}$ examined the effects of materials placed against the pulp in direct pulp caps and learned that the seal of the tooth was more important than the material used. This finding also suggests that secondary caries, perforation, and poor sealing are factors in the failed longevity of direct pulp capping. Hebling et al. ${ }^{45-46}$ discredited the use of All Bond 2 composite as a direct pulp capping agent. Torabinejad and Pitt Ford ${ }^{47}$ and Witherspoon and Robertson ${ }^{48}$ compared mineral trioxide aggregate (MTA) and $\mathrm{Ca}(\mathrm{OH})_{2}$ as pulp capping agents. All three reports stated that MTA was more effective because there was less inflammation (according to Torabinejad and Pitt Ford, there was none) and more homogeneous hard tissue/dentin bridge formation. Menezes et al. ${ }^{49}$ found no significant difference in hard tissue bridging or inflammation when using ProRoot MTA, Angelus MTA, and regular or white Portland cements to pulp cap direct exposures on dogs.

\section{What is needed for developing a new direct pulp capping material with better clinical outcomes?}

In the 1960s and 1970s, glucocorticoids (steroids) combined with antibiotics were frequently used in an attempt to control pulpal pain and suppress pulpal inflammation ${ }^{50}$. Reports of poor wound healing and even pulpal necrosis started to emerge ${ }^{50-52}$, so steroids are no longer used for direct pulp capping. During this period, there were few concerns about infection after completion of the direct pulp capping treatment. Many of the treatments in these studies may have failed due to secondary problems such as complications related to technical control that compromised efforts to avoid bacterial leakage. Recent new knowledge about the cellular and molecular basis of the inflammatory and repair processes of the pulp ${ }^{53-56}$, and the advent of modern pharmacologic and bioengineering strategies, such as drug delivery systems, have created many avenues for development of improved and predictable treatment methods for infected and inflamed pulps.

In light of the above-mentioned new knowledge, Rutherford and colleagues ${ }^{57-58}$ worked on a vital pulp therapy in the 1990s using bone morphogenetic protein (BMP), also known as osteogenic protein-1, which induced reparative dentin formation in experimental models of large direct pulp exposures in permanent teeth. No specific attempt was made to induce pulpitis before the exposure and partial amputation of the vital pulp. Soft tissue regeneration followed by the regeneration of regular dentin would be a more favorable outcome.

Dentin contains many proteins capable of stimulating reparative responses. Demineralization of the dental tissues can lead to the release of growth factors entrapped in the dentin matrix following the application of cavity etching agents or restorative materials and even when caries develop ${ }^{59}$. Once released, these growth factors play key roles in signaling many of the events involved in reparative dentin formation ${ }^{60-61}$. Growth factors, especially those of the transforming growth factor-beta (TGF-beta) family, are important in cellular signaling for the differentiation and stimulation of dentin matrix secretion. These growth factors are secreted by dentin-forming cells during tooth development and deposited within the organic matrix preceding the formation of the mineralized tissue ${ }^{62-64}$ where they remain protected in an active 
form through interaction with other components ${ }^{65}$. The addition of purified dentin protein fractions stimulates an increase in dentin matrix secretion 66 .

For exposed pulp, researchers have reported using TGF-beta together with a drug delivery vehicle to administer an anti-inflammatory agent to the pulp. In 1998, Hu et al. ${ }^{67}$ suggested using TGF-beta-1 material as a direct pulp capping agent. With this method, mechanically exposed pulp treated with TGF-beta, along with a sterile absorbable collagen membrane, showed significantly improved soft and hard tissue healing in rat molars after three weeks. However, the drawbacks of the study were the inclusion of mechanically exposed pulp (with no previous caries involvement) and a poor outcome description of the collagen membrane used as a drug delivery vehicle for TGF-beta-1. In 2007, Zhang et al. ${ }^{68}$ evaluated the effect of a calcium phosphate material equipped with poly (lactic-co-glycolic acid) (PLGA) microspheres for pulp capping and measured the dentin bridge formation using various concentrations of TGF-beta-1. The composition with $400 \mathrm{ng}$ TGF-beta-1 was able to trigger the resident stem cells in goat incisor pulp to differentiate into odontoblast-like cells and to induce the formation of tertiary dentin, suggesting that this material might be a good candidate for vital pulp therapy. The weaknesses of this study included the use of mechanically exposed pulp (no previous caries involvement), the production and manipulation methods, and insufficient degradation of the PLGA polymer.

Based on the information above, it is hypothesized that the application of anti-inflammation factor(s) to caries-exposed pulp limits the inflammatory response, accelerates tissue regeneration, and lead to the deposition of mineralized dentin of physiologic quality. The advantage of this approach is that the increased risk of pulpal necrosis or excessive calcification resulting from calcium hydroxide-induced tissue irritation is avoided. The local application of antibiotics, together with direct pulp capping material, may be more effective at removing bacteria ${ }^{69-70}$. While it is known that direct pulp capping treatment is theoretically ideal at preserving vital pulp, it is not known how to transform the existing pulp from an inflamed status (pulpitis) to a non-inflamed status (normal pulp). It is speculated that if an antiinflammation factor(s) placed in the caries-exposed pulp limits the inflammatory response, possible toxic substances inside the pulp will be cleaned out once a non-inflamed status (normal pulp) is achieved. These developments in treatment demonstrate that a critical need exists to fine-tune the biologically based therapeutics that promote the continued formation of a new dentin-pulp complex and that restore vitality by stimulating the regrowth of pulpal tissue.

\section{Three future directions}

This review summarized three directions for future endodontic therapy.

First, the development of a novel anti-inflammatory direct pulp capping material for caries exposed to the pulp in permanent teeth with a mature apex is of great interest. A new dentinpulp complex could be regenerated through the use of such a material to increase the success rate of pulp capping and stimulate pulp regeneration at the capping site. Anti-inflammatory medication mixed with a novel bioengineered drug delivery vehicle would be an effective direct pulp-capping material for caries-exposed pulp.

Second, a new material to induce pulp tissue calcification limited to the coronal part of the pulp would also be beneficial. This material would be used for deeper direct pulp capping or pulpotomies to induce coronal (partial) pulp calcification or calcification of the pulp in the root canal when the coronal pulp is already infected. Complete calcification of the pulp (calcific metamorphosis) is abnormal and should be avoided, as it is a sign of a biological breakdown in tissue function. Pulp wound healing, a solid hard tissue deposit consisting of tubular dentin, should stop when the repair within the coronal part of the pulp is complete. 
Finally, pulp tissue regeneration is needed if all the pulp is necrotic. The ability of pulp to regenerate using the latest tissue engineering techniques might be utilized. The key elements involved in tissue engineering are (1) stem cells, (2) morphogens or growth factors, and (3) a scaffold of an extracellular matrix ${ }^{71-72}$. A biomimetic scaffold might help direct the differentiation of dental stem cells and the subsequent regeneration of a functional dentin-pulp complex.

\section{Acknowledgments}

The authors thank Ms. Jeanne Santa Cruz (Texas A\&M Health Science Center Baylor College of Dentistry) for the critical editing. The authors also thank Dr. Kamran E. Safavi and Dr. Larz S.W. Spångberg (University of Connecticut) for their helpful comments.

This work was supported by NIH KL2RR024983 (TK) and UL1 RR024982, entitled, "North and Central Texas Clinical and Translational Science Initiative" (Milton Packer, PI) from the National Center for Research Resources (NCRR), a component of the National Institutes of Health (NIH), and NIH Roadmap for Medical Research. Its contents are solely the responsibility of the authors and do not necessarily represent the official views of the NCRR or NIH. Information on NCRR is available at http://www.ncrr.nih.gov/. Information on Reengineering the Clinical Research Enterprise can be obtained from http://nihroadmap.nih.gov/clinicalresearch/overview-translational.asp.

\section{References}

[1]. Bergenholtz G, Mjor IA, Cotton WR, Hanks CT, Kim S, Torneck CD, et al. The biology of dentin and pulp. Consensus report. J Dent Res Apr;1985 64:631-3. [PubMed: 3857267]

[2]. Pashley DH. Dynamics of the pulpo-dentin complex. Crit Rev Oral Biol Med 1996;7(2):104-33. [PubMed: 8875027]

[3]. Couve E. Ultrastructural changes during the life cycle of human odontoblasts. Arch Oral Biol 1986;31 (10):643-51. [PubMed: 3477208]

[4]. Kakehashi S, Stanley HR, Fitzgerald RJ. The Effects of Surgical Exposures of Dental Pulps in GermFree and Conventional Laboratory Rats. Oral Surg Oral Med Oral Pathol Sep;1965 20:340-9. [PubMed: 14342926]

[5]. Sundqvist, G. Bacteriological studies of necrotic dental pulps. Umeå; Sweden: 1976.

[6]. 2005-06 Survey of Dental Services Rendered and Distribution of Dentists in the United States by Region and State. American Dental Association, Survey Center; Chicago: 2007.

[7]. Figdor D. Apical periodontitis: a very prevalent problem. Oral Surg Oral Med Oral Pathol Oral Radiol Endod Dec;2002 94(6):651-2. [PubMed: 12464886]

[8]. Cheung GS. Endodontic failures--changing the approach. Int Dent J Jun;1996 46(3):131-8. [PubMed: 8886865]

[9]. Randow K, Glantz PO. On cantilever loading of vital and non-vital teeth. An experimental clinical study. Acta Odontol Scand Oct;1986 44(5):271-7. [PubMed: 3544657]

[10]. Stanley HR. Criteria for standardizing and increasing credibility of direct pulp capping studies. Am J Dent Jan;1998 11:S17-34. [PubMed: 9760878]

[11]. Bender IB. Reversible and irreversible painful pulpitides: diagnosis and treatment. Aust Endod J Apr;2000 26(1):10-4. [PubMed: 11359291]

[12]. Bergenholtz G, Spangberg L. Controversies in Endodontics. Critical Reviews in Oral Biology \& Medicine March 1;2004 15(2):99-114. 2004. [PubMed: 15059945]

[13]. Langeland K, Dowden WE, Tronstad L, Langeland LK. Human pulp changes of iatrogenic origin. Oral Surg Oral Med Oral Pathol Dec;1971 32(6):943-80. [PubMed: 4942993]

[14]. Lin L, Langeland K. Light and electron microscopic study of teeth with carious pulp exposures. Oral Surg Oral Med Oral Pathol Mar;1981 51(3):292-316. [PubMed: 6938890]

[15]. Zander H. Reaction of the pulp to calcium hydroxide. J Dent Res 1939;12:373-9.

[16]. Nyborg H. Healing processes in the pulp on capping; a morphologic study; experiments on surgical lesions of the pulp in dog and man. Acta Odontol Scand 1955;13(suppl. 16):1-130. [PubMed: 14387628] 
[17]. Schroder U. Effects of calcium hydroxide-containing pulp-capping agents on pulp cell migration, proliferation, and differentiation. J Dent Res Apr;1985 64:541-8. [PubMed: 3857254]

[18]. Yamamura T. Differentiation of pulpal cells and inductive influences of various matrices with reference to pulpal wound healing. J Dent Res Apr;1985 64:530-40. [PubMed: 3857253]

[19]. Hermann B. Dentinobliteration der Wurzelkanäle nach Behandlung mit Calzium. Zahnärztl Rundschau 1930;39:888-98.

[20]. Hermann, B. Calciumhydroxyd als Mittel zum Behandel und Füllen von Zahnwurzelkanälen Würzburg. Faculty of Medicine, University of Würzburg; Germany: 1920.

[21]. Haskell EW, Stanley HR, Chellemi J, Stringfellow H. Direct pulp capping treatment: a long-term follow-up. J Am Dent Assoc Oct;1978 97(4):607-12. [PubMed: 281402]

[22]. Cvek M. A clinical report on partial pulpotomy and capping with calcium hydroxide in permanent incisors with complicated crown fracture. J Endod Aug;1978 4(8):232-7. [PubMed: 283188]

[23]. Horsted P, Sandergaard B, Thylstrup A, El Attar K, Fejerskov O. A retrospective study of direct pulp capping with calcium hydroxide compounds. Endod Dent Traumatol Feb;1985 1(1):29-34. [PubMed: 3858095]

[24]. Caliskan MK. Pulpotomy of carious vital teeth with periapical involvement. Int Endod J May;1995 28(3):172-6. [PubMed: 8626202]

[25]. Lim KC, Kirk EE. Direct pulp capping: a review. Endod Dent Traumatol Oct;1987 3(5):213-9. [PubMed: 3315643]

[26]. Maryniuk GA, Haywood VB. Placement of cast restorations over direct pulp capping procedures: a decision analytic approach. J Am Dent Assoc Feb;1990 120(2):183-7. [PubMed: 2105346]

[27]. Ward J. Vital pulp therapy in cariously exposed permanent teeth and its limitations. Aust Endod J Apr;2002 28(1):29-37. [PubMed: 12360679]

[28]. Bergenholtz G. Advances since the paper by Zander and Glass (1949) on the pursuit of healing methods for pulpal exposures: historical perspectives. Oral Surg Oral Med Oral Pathol Oral Radiol Endod Aug;2005 100(2 Suppl):S102-8. [PubMed: 16037786]

[29]. Tronstad L, Mjor IA. Capping of the inflamed pulp. Oral Surg Oral Med Oral Pathol Sep;1972 34 (3):477-85. [PubMed: 4625987]

[30]. Al-Hiyasat AS, Barrieshi-Nusair KM, Al-Omari MA. The radiographic outcomes of direct pulpcapping procedures performed by dental students: a retrospective study. J Am Dent Assoc Dec; 2006 137(12):1699-705. [PubMed: 17138715]

[31]. Barthel CR, Rosenkranz B, Leuenberg A, Roulet JF. Pulp capping of carious exposures: treatment outcome after 5 and 10 years: a retrospective study. J Endod Sep;2000 26(9):525-8. [PubMed: 11199794]

[32]. Christensen GJ. Pulp capping 1998. J Am Dent Assoc Sep;1998 129(9):1297-9. [PubMed: 9766112]

[33]. Stockton LW. Vital pulp capping: a worthwhile procedure. J Can Dent Assoc Jun;1999 65(6):32831. [PubMed: 10412240]

[34]. Granath L-E, Hagman G. Experimental Pulpotomy in Human Bicuspids with Reference to Cutting Technique. Acta Odontologica Scandinavica 1971;29(2):155-63. [PubMed: 5283990]

[35]. Schroder U. Evaluation of healing following experimental pulpotomy of intact human teeth and capping with calcium hydroxide. Odontol Revy 1972;23(3):329-40. [PubMed: 4507744]

[36]. Schroder U, Granath LE. Scanning electron microscopy of hard tissue barrier following experimental pulpotomy of intact human teeth and capping with calcium hydroxide. Odontol Revy 1972;23(2):211-20. [PubMed: 4504495]

[37]. Schroder U, Granath LE. Early reaction of intact human teeth to calcium hydroxide following experimental pulpotomy and its significance to the development of hard tissue barrier. Odontol Revy 1971;22(4):379-95. [PubMed: 5292154]

[38]. Cvek M, Granath L, Cleaton-Jones P, Austin J. Hard tissue barrier formation in pulpotomized monkey teeth capped with cyanoacrylate or calcium hydroxide for 10 and 60 minutes. J Dent Res Jun;1987 66(6):1166-74. [PubMed: 3476588]

[39]. Mejare I, Cvek M. Partial pulpotomy in young permanent teeth with deep carious lesions. Endod Dent Traumatol Dec;1993 9(6):238-42. [PubMed: 8143574] 
[40]. Cvek M, Lundberg M. Histological appearance of pulps after exposure by a crown fracture, partial pulpotomy, and clinical diagnosis of healing. J Endod Jan;1983 9(1):8-11. [PubMed: 6590761]

[41]. Granath LE, Hagman G. Experimental pulpotomy in human bicuspids with reference to cutting technique. Acta Odontol Scand Jun;1971 29(2):155-63. [PubMed: 5283990]

[42]. Glass RL, Zander HA. Pulp healing. J Dent Res Apr;1949 28(2):97-107. [PubMed: 18118442]

[43]. Zander HA, Glass RL. The healing of phenolized pulp exposures. Oral Surg Oral Med Oral Pathol Jun;1949 2(6):803-10. [PubMed: 18130486]

[44]. Cox CF, Bergenholtz G, Heys DR, Syed SA, Fitzgerald M, Heys RJ. Pulp capping of dental pulp mechanically exposed to oral microflora: a 1-2 year observation of wound healing in the monkey. J Oral Pathol Feb;1985 14(2):156-68. [PubMed: 3920366]

[45]. Hebling J, Giro EM, Costa CA. Biocompatibility of an adhesive system applied to exposed human dental pulp. J Endod Oct;1999 25(10):676-82. [PubMed: 10687527]

[46]. Hebling J, Giro EM, Costa CA. Human pulp response after an adhesive system application in deep cavities. J Dent Nov;1999 27(8):557-64. [PubMed: 10528973]

[47]. Torabinejad M, Pitt Ford TR. Root end filling materials: a review. Endod Dent Traumatol Aug; 1996 12(4):161-78. [PubMed: 9028180]

[48]. Witherspoon DJ, Robertson HM. Neutral evolution of ten types of mariner transposons in the genomes of Caenorhabditis elegans and Caenorhabditis briggsae. J Mol Evol Jun;2003 56(6):75169. [PubMed: 12911038]

[49]. Menezes R, Bramante CM, Letra A, Carvalho VG, Garcia RB. Histologic evaluation of pulpotomies in dog using two types of mineral trioxide aggregate and regular and white Portland cements as wound dressings. Oral Surg Oral Med Oral Pathol Oral Radiol Endod Sep;2004 98(3):376-9. [PubMed: 15356480]

[50]. Watts A, Paterson RC. The response of the mechanically exposed pulp to prednisolone and triamcinolone acetonide. Int Endod J Jan;1988 21(1):9-16. [PubMed: 3273294]

[51]. Paterson RC. Corticosteroids and the exposed pulp. Br Dent J Mar 2;1976 140(5):174-7. [PubMed: 1061609]

[52]. Langeland K. Management of the inflamed pulp associated with deep carious lesion. J Endod Apr; 1981 7(4):169-81. [PubMed: 6939782]

[53]. Tziafas, D. Reparative dentinogenesis. A monograph on the dentinogenic potential of dental pulp. University Studio Press; Thessaloniki, Greece: 1997.

[54]. Jontell M, Okiji T, Dahlgren U, Bergenholtz G. Immune defense mechanisms of the dental pulp. Crit Rev Oral Biol Med 1998;9(2):179-200. [PubMed: 9603235]

[55]. Byers MR, Narhi MV. Dental injury models: experimental tools for understanding neuroinflammatory interactions and polymodal nociceptor functions. Crit Rev Oral Biol Med 1999;10(1):4-39. [PubMed: 10759425]

[56]. Tziafas D, Smith AJ, Lesot H. Designing new treatment strategies in vital pulp therapy. J Dent Feb; 2000 28(2):77-92. [PubMed: 10666965]

[57]. Rutherford RB, Spangberg L, Tucker M, Rueger D, Charette M. The time-course of the induction of reparative dentine formation in monkeys by recombinant human osteogenic protein-1. Arch Oral Biol Oct;1994 39(10):833-8. [PubMed: 7741652]

[58]. Rutherford B, Fitzgerald M. A new biological approach to vital pulp therapy. Crit Rev Oral Biol Med 1995;6(3):218-29. [PubMed: 8785262]

[59]. Murray PE, Smith AJ. Saving pulps--a biological basis. An overview. Prim Dent Care Jan;2002 9 (1):21-6. [PubMed: 11901786]

[60]. Tziafas D. Basic mechanisms of cytodifferentiation and dentinogenesis during dental pulp repair. Int J Dev Biol Feb;1995 39(1):281-90. [PubMed: 7626418]

[61]. Tziafas D, Alvanou A, Panagiotakopoulos N, Smith AJ, Lesot H, Komnenou A, et al. Induction of odontoblast-like cell differentiation in dog dental pulps after in vivo implantation of dentine matrix components. Arch Oral Biol Oct;1995 40(10):883-93. [PubMed: 8526798]

[62]. D’Souza RN, Happonen RP, Ritter NM, Butler WT. Temporal and spatial patterns of transforming growth factor-beta 1 expression in developing rat molars. Arch Oral Biol 1990;35(12):957-65. [PubMed: 2076061] 
[63]. D’Souza RN, Flanders K, Butler WT. Colocalization of TGF-beta 1 and extracellular matrix proteins during rat tooth development. Proc Finn Dent Soc 1992;88(Suppl 1):419-26. [PubMed: 1508900]

[64]. Roberts-Clark DJ, Smith AJ. Angiogenic growth factors in human dentine matrix. Arch Oral Biol Nov;2000 45(11):1013-6. [PubMed: 11000388]

[65]. Smith AJ, Matthews JB, Hall RC. Transforming growth factor-beta1 (TGF-beta1) in dentine matrix. Ligand activation and receptor expression. Eur J Oral Sci Jan;1998 106(Suppl 1):179-84. [PubMed: 9541223]

[66]. Smith AJ, Murray PE, Sloan AJ, Matthews JB, Zhao S. Trans-dentinal stimulation of tertiary dentinogenesis. Adv Dent Res Aug;2001 15:51-4. [PubMed: 12640740]

[67]. Hu CC, Zhang C, Qian Q, Tatum NB. Reparative dentin formation in rat molars after direct pulp capping with growth factors. J Endod Nov;1998 24(11):744-51. [PubMed: 9855826]

[68]. Zhang W, Walboomers XF, Jansen JA. The formation of tertiary dentin after pulp capping with a calcium phosphate cement, loaded with PLGA microparticles containing TGF-beta1. J Biomed Mater Res A May;2008 85(2):439-44. [PubMed: 17701971]

[69]. Yanpiset K, Trope M. Pulp revascularization of replanted immature dog teeth after different treatment methods. Endod Dent Traumatol Oct;2000 16(5):211-7. [PubMed: 11202884]

[70]. Windley W 3rd, Teixeira F, Levin L, Sigurdsson A, Trope M. Disinfection of immature teeth with a triple antibiotic paste. J Endod Jun;2005 31(6):439-43. [PubMed: 15917683]

[71]. Reddi AH. Role of morphogenetic proteins in skeletal tissue engineering and regeneration. Nat Biotechnol Mar;1998 16(3):247-52. [PubMed: 9528003]

[72]. Nakashima M, Reddi AH. The application of bone morphogenetic proteins to dental tissue engineering. Nat Biotechnol Sep;2003 21(9):1025-32. [PubMed: 12949568] 